\title{
Effect of Protonation and Deprotonation on the Gas-Phase Reactivity of Fluorinated 1,2,4-Triazines
}

\author{
Gianluca Giorgi, ${ }^{\mathrm{a}}$ Antonio Palumbo Piccionello, ${ }^{\mathrm{b}}$ Andrea Pace, ${ }^{\mathrm{b}}$ and \\ Silvestre Buscemi ${ }^{\mathrm{b}}$ \\ a Dipartimento di Chimica, Università degli Studi di Siena, Siena, Italy \\ b Dipartimento di Chimica Organica "E. Paternò", Università degli Studi di Palermo, Palermo, Italy
}

Positive and negative electrospray mass spectrometry (MS), in-time and in-space $\mathrm{MS}^{n}$ experiments, high-resolution and accurate mass measurements obtained with an Orbitrap, together with density functional theory calculations have been used to study the gas-phase ion chemistry of a series of fluorinated 1,2,4-triazines. As a result of low-energy collision-induced dissociations, occurring in an ion trap and in a triple quadrupole, their protonated and deprotonated molecules show interesting features depending on the nature and structure of the precursor ions. The occurrence of elimination/hydration reactions produced by positive ions in the ion trap is noteworthy. Decompositions of deprotonated molecules, initiated by elimination of a hydroxyl radical from $[\mathrm{M}-\mathrm{H}]^{-}$, are dominated by radical anions. Theoretical calculations have allowed us to obtain information on atom sites involved in the protonation and deprotonation reactions. (J Am Soc Mass Spectrom 2008, 19, 686-694) (c) 2008 American Society for Mass Spectrometry

$\mathrm{T}$ Triazines constitute a class of interesting compounds that find their applications in several fields, such as pharmaceutical chemistry [1], phytochemistry [2], biology [3, 4], catalysis [5], and supramolecular chemistry [6].

In the last decades different synthetic approaches have been set up for obtaining new fluorinated heterocyclic compounds [7]. Recently, we developed a new synthetic procedure for preparing series of fluorinated 1,2,4-triazines through ANRORC (addition of nucleophile, ring-opening, and ring-closure) rearrangements of 5-perfluoroalkyl-1,2,4-oxadiazoles [8].

In the framework of research aimed at studying the gas-phase ion chemistry of heterocyclic molecules [9], we seek to present here a mass spectrometry (MS) and a theoretical study of compounds 1-4 (Scheme 1).

These compounds are particularly suitable and interesting for their gas-phase ion chemistry because they can be protonated or deprotonated by using electrospray ionization (ESI). It follows that it is possible to evaluate the effects of protonation and deprotonation on their gas-phase decompositions. Multiple MS separation stages arising from low-energy collision-induced dissociations (CIDs) occurring both in an ion trap (IT) and in a triple quadrupole (QqQ) mass spectrometer have been carried out and compared. High-resolution and accurate mass measurements, obtained by using an

Address reprint requests to Dr. Gianluca Giorgi, Università di Siena, Dipartimento di Chimica, via Aldo Moro, 53100 Siena, Italy. E-mail: gianluca.giorgi@unisi.it
Orbitrap analyzer, have allowed us to determine the elemental composition for each ionic species detected in MS and $\mathrm{MS}^{n}$ spectra as a result of electrospray ionization. Because in each molecule different atoms might be involved in proton addition or abstraction, density functional theory (DFT) calculations have been carried out on different structures of protonated and deprotonated molecules of compound $\mathbf{1}$.

\section{Experimental}

\section{Synthesis of the Compounds and Mass Spectrometry}

Compounds 1-4 were prepared according to the procedure described in Buscemi et al. [8, 10].

Electrospray measurements were carried out on an LCQ-DECA ion trap and on an LTQ-XP-Orbitrap instrument (Thermo Fisher Scientific, Bremen, Germany). Operating conditions of the ESI source were as follows: spray voltage, $4.5 \mathrm{kV}$; capillary temperature, $200^{\circ} \mathrm{C}$; sheath gas (nitrogen) flow rate, approximately $0.75 \mathrm{~L}$ $\mathrm{min}^{-1}$. Ultrapure helium was the collision gas; CID collision energy: $0.5-1.0 \mathrm{eV}$ (laboratory frame). The Orbitrap analyzer was operating in the resolution range 30,000-100,000 and calibrated using the manufacturer's calibration mixture. Mass accuracies $<2$ ppm were determined before and after each session of experiments. In all, 30-50 scans were recorded and averaged for accurate mass measurements. 


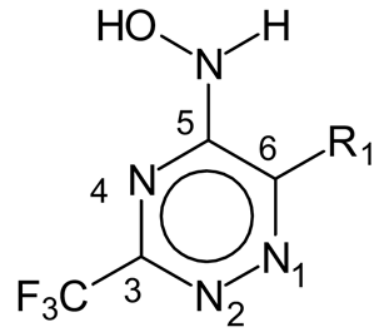

1. $\mathrm{R}_{1}=\mathrm{OH}$

2. $\mathrm{R}_{1}=\mathrm{Ph}$<smiles></smiles>

3. $\mathrm{R}_{2}=\mathrm{CF}_{3}$

4. $\mathrm{R}_{2}=\mathrm{C}_{3} \mathrm{~F}_{7}$
Scheme 1.

Electrospray triple quadrupole measurements were carried out on a VG-Quattro LC (Waters, Manchester, UK) mass spectrometer. Spray voltage was $3.5 \mathrm{kV}$; the sampling cone was set at $5 \mathrm{~V}$; and the counter-electrode potential was $500 \mathrm{~V}$. The source temperature was $80^{\circ} \mathrm{C}$. Nitrogen was used as nebulizer and drying gas at flow rates of 60 and $400 \mathrm{~L} \mathrm{~h}^{-1}$, respectively. CID experiments were carried out using argon as target gas at a pressure of about $1.4 \times 10^{-3}$ bar. The laboratory energy was in the 20 - to $25-\mathrm{eV}$ range.

Working solutions were introduced into each mass spectrometer using a syringe pump at a flow rate of 5 $\mu \mathrm{L} \min ^{-1}$.

The reported values of relative intensities in MS/MS spectra are the mean of 20-50 scans.

\section{Theoretical Calculations}

Density functional theory calculations were performed on different structures proposed for protonated and deprotonated molecules by using Gaussian 03 [11], implemented on an IBM SP RS/6000 Power 5 supercomputer at Cineca in Bologna, Italy. All geometries were fully optimized without any constraints at the Becke 3LYP (B3LYP) [12] method with the 6-31G(d,p) level of theory. The final lowest energy geometries were confirmed as a minimum on the potential energy surface by normal-mode vibrational frequency calculations that produced all real frequencies. Zero-point energies and statistical thermodynamic properties at $298.15 \mathrm{~K}$ and 1 atm were calculated at the B3LYP-6-31G(d,p) level of theory. A scaling factor of 0.9613 was used for zero-point energies [13].

\section{Results and Discussion}

\section{Gas-Phase Behavior of Protonated Molecules of Compounds 1-4}

The ESI (+) mass spectra of compounds 1-4 are characterized by protonated molecules and sodium adducts, whereas no other fragment ion is detected.
DFT calculations carried out on $[\mathbf{1}+\mathrm{H}]^{+}$cations, protonated at different sites, suggest that protonation on nitrogen atoms is highly favored, with $\mathrm{N}(2)$ being the preferred site, followed by N(4) and N(1) (Figure 1, Table 1).

Product ion CID spectra obtained in the ion trap by selecting the species $[\mathrm{M}+\mathrm{H}]^{+}$of compounds $1-4$ show common interesting features (Figure 2). The presence of puzzling ions that differ 2, 22, and $24 \mathrm{u}$ from their precursors and that of clusters of ions that differ $2 \mathrm{u}$ from each other [14] is noteworthy. As an example, the product ion MS/MS spectrum of $[\mathbf{1}+\mathrm{H}]^{+}(\mathrm{m} / \mathrm{z} 197$, Figure 2, top) shows the presence of ions at $m / z 195$, differing $2 \mathrm{u}$ from the precursor ion. Other groups of ions differing $2 \mathrm{u}$ from each other are also present at $m / z 173,175,177$, and at $m / z 155,157$. Among them, ionic species at $m / z$ 173, which differ $24 \mathrm{u}$ from $[1+\mathrm{H}]^{+}$, are the most intense (Figure 2, top). This behavior can be explained by the occurrence of hydration/elimination reactions of trapped protonated molecules, mainly consisting of successive eliminations of HF followed by nucleophilic addition of water present in the ion trap [14].

This behavior resembles that recently observed for protonated bisubstituted isoquinolines that, when submitted to $\mathrm{MS}^{3}$ and $\mathrm{MS}^{4}$ experiments in an ion trap, show nominal elimination of $11 \mathrm{u}$, due to the loss of HCN and concomitant addition of oxygen [15].

For compounds 1-3, the reaction pathways occurring as a result of CID are initiated by loss of HF from the protonated molecule, thus forming a carbocation $[(\mathrm{M}+\mathrm{H})-20]^{+}$. The loss of HF is promoted by the protonation at $\mathrm{N}(2)$ that theoretical calculations suggest as the most favorable protonation site. A successive loss of $\mathrm{HF}$ produces the ions $[(\mathrm{M}+\mathrm{H})-40]^{+}$. Alternatively, the species $[(\mathrm{M}+\mathrm{H})-20]^{+}$can add, through a 1,3nucleophilic addition, a water molecule yielding the cation $[(\mathrm{M}+\mathrm{H})-2]^{+}$. A further elimination of one or two molecules of $\mathrm{HF}$ yields ions formally due to $[(\mathrm{M}+\mathrm{H})-22]^{+}$and $[(\mathrm{M}+\mathrm{H})-42]^{+}$, respectively. This latter can add another molecule of water, thus producing the species $[(\mathrm{M}+\mathrm{H})-24]^{+}$.

Protonated molecules can also decompose by elimination of a water molecule followed by $\mathrm{HF}$, thus producing ions $[(\mathrm{M}+\mathrm{H})-18]^{+}$and $[(\mathrm{M}+\mathrm{H})-38]^{+}$, respectively. These latter can undergo a hydration reaction yielding the species $[(\mathrm{M}+\mathrm{H})-20]^{+}$, whose reactivity was reported earlier. Elemental compositions of all these ionic species have been confirmed by accurate mass measurements carried out under high-resolution conditions.

Gas-phase decompositions strictly dependent on the chemical structure of the ions are also observed. One example is the fragmentation pathway that yields ions at $m / z 151$ in the IT-MS ${ }^{2}$ spectrum of $[\mathbf{1}+\mathrm{H}]^{+}$(Figure 2, top). Accurate mass measurements have allowed us to determine that their elemental composition is $\mathrm{C}_{3} \mathrm{H}_{2} \mathrm{~N}_{4} \mathrm{~F}_{3}$ (calcd 151.0226, measured 151.0224), indicating a nom- 


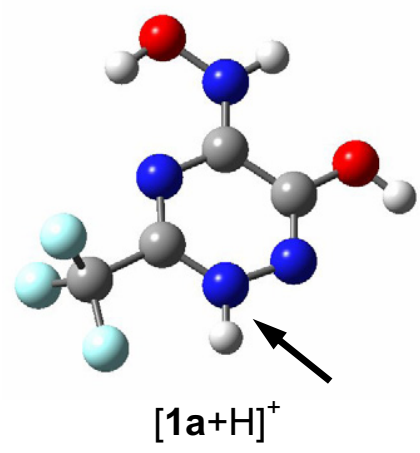

$\Delta \mathrm{E}=$

0

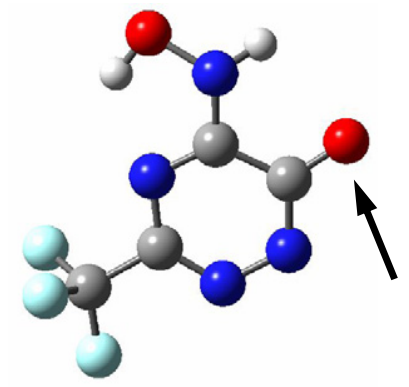

[1d-H]

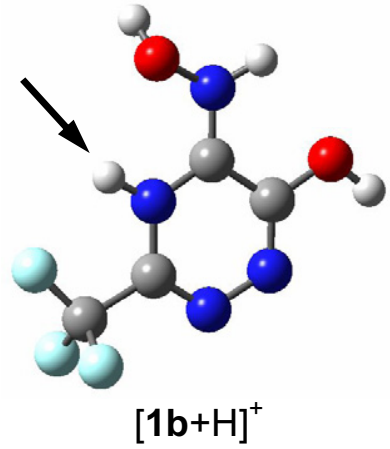

12.91

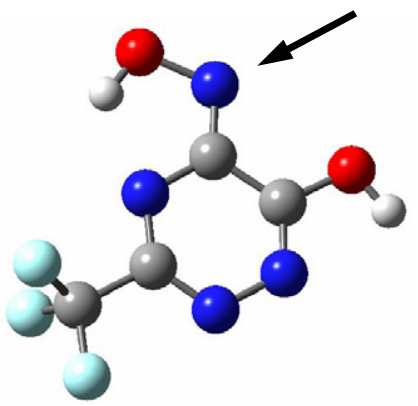

$[1 \mathrm{e}-\mathrm{H}]^{-}$

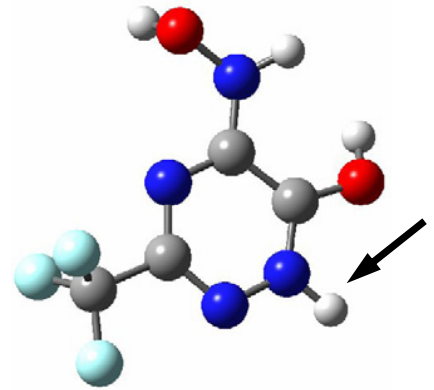

$[1 \mathrm{c}+\mathrm{H}]^{+}$

19.47

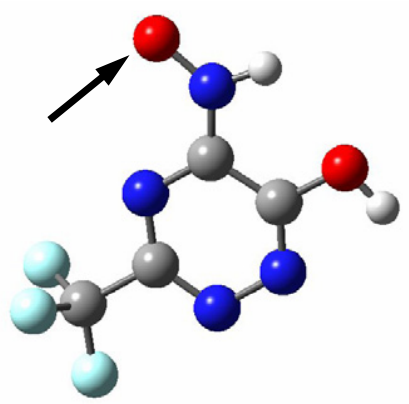

$[1 \mathrm{f}-\mathrm{H}]^{-}$

$\Delta \mathrm{E}=$

0

4.61

18.19

Figure 1. Energy-minimized structures for protonated (top row) and deprotonated (bottom row) molecules of compound 1 . Arrows indicate the protonation/deprotonation site. $\Delta \mathrm{E}$ values are in $\mathrm{kcal}$ $\mathrm{mol}^{-1}$.

inal loss of $\mathrm{CH}_{2} \mathrm{O}_{2}$ from the protonated molecule. This loss might be ascribed to the elimination of formic acid, but it seems unlikely because it should require deep rearrangements. Thus we propose that ions at $\mathrm{m} / \mathrm{z} 151$ are produced by consecutive losses of water and $\mathrm{CO}$ from $[\mathbf{1}+\mathrm{H}]^{+}$.

As a result of low-energy collision-induced dissociations occurring in the ion trap, the protonated species $[2+\mathrm{H}]^{+}(m / z 257)$ shows an abundant elimination of a water molecule. Distinctive fragmentation pathways, observed in $\mathrm{MS}^{3}$ experiments by selecting the cation $\left[(2+\mathrm{H})-\mathrm{H}_{2} \mathrm{O}\right]^{+}$as precursor ion, yield the species

Table 1. Energy values of minimized species produced by 1

\begin{tabular}{lcccc}
\hline Species & $\begin{array}{c}\text { B3LYP } \\
\text { 6-31G(d,p) }\end{array}$ & ZPVE $^{\mathrm{b}}$ & $\begin{array}{c}\text { SCF }+ \\
\text { ZPVE }^{\mathrm{a}}\end{array}$ & $\begin{array}{c}\Delta \mathrm{E} \\
(\mathrm{SCF}+ \\
\text { ZPVE) }^{\mathrm{c}}\end{array}$ \\
\hline \hline$[\mathbf{1 a + H}]^{+}$ & -823.489023 & 0.104296 & -823.384727 & 0 \\
{$[\mathbf{1 b}+\mathrm{H}]^{+}$} & -823.467561 & 0.103416 & -823.364145 & 12.91 \\
{$[\mathbf{1 c}+\mathrm{H}]^{+}$} & -823.456856 & 0.103158 & -823.353698 & 19.47 \\
{$[\mathbf{1 d}-\mathrm{H}]^{-}$} & -822.587675 & 0.078325 & -822.509350 & 0 \\
{$[\mathbf{1 e}-\mathrm{H}]^{-}$} & -822.580493 & 0.078488 & -822.502005 & 4.61 \\
{$[\mathbf{1 f}-\mathrm{H}]^{-}$} & -822.558682 & 0.078321 & -822.480361 & 18.19 \\
\hline
\end{tabular}

aUnits of Hartree.

bZero-point vibrational energies corrected by 0.9613 [13]; units of Hartree/particle.

${ }^{\mathrm{c}} \mathrm{kcal} \mathrm{mol}^{-1}$.
$\left[\left(2+\mathrm{H}-\mathrm{H}_{2} \mathrm{O}\right)-\mathrm{HF}-\mathrm{N}_{2}\right]^{+}$and $\left[\left(2+\mathrm{H}-\mathrm{H}_{2} \mathrm{O}\right)-\mathrm{CF}_{3} \mathrm{CN}\right]^{+}$ at $\mathrm{m} / \mathrm{z} 191$ and 144, respectively, whose elemental compositions have been confirmed by accurate mass measurements.

Compound 4 , bearing a $-\mathrm{C}_{3} \mathrm{~F}_{7}$ moiety at position 3 of the triazine ring, has a different behavior. In fact the IT-MS ${ }^{2}$ spectrum obtained by selecting its protonated molecule $(m / z$ 311) shows that the initial loss of HF occurs to a very small extent, producing ions at $m / z 291$ whose relative abundance is about $1 \%$. For both compounds 3 and 4 , the most intense product ions are $[(\mathrm{M}+\mathrm{H})-46]^{+}$and, similarly to 1 , they are attributed to consecutive losses of $\mathrm{H}_{2} \mathrm{O}$ and $\mathrm{CO}$. Hydration of fragment ions is quite scarce for 4 and it occurs only for those at $m / z$ 223, produced by a $\mathrm{C}_{2} \mathrm{H}_{2} \mathrm{~N}_{2}$ loss from $\left[(4+\mathrm{H})-\mathrm{H}_{2} \mathrm{O}-\mathrm{CO}\right]^{+}(\mathrm{m} / \mathrm{z} 265)$. Addition of one water molecule to the former ions produces the species at $\mathrm{m} / \mathrm{z}$ 241.

When low-energy collision-induced dissociations occur in a triple quadrupole, different reaction pathways are activated in comparison with those detected in the ion trap: hydration reactions, which have great importance inside the ion trap, are undetectable in the QqQ regime. Furthermore, the possibility offered by the triple quadrupole of scanning the low $\mathrm{m} / \mathrm{z}$ region allows one to detect product ions with low $m / z$ values. Finally, $\mathrm{MS}^{2}$ spectra obtained in the triple quadrupole generally 


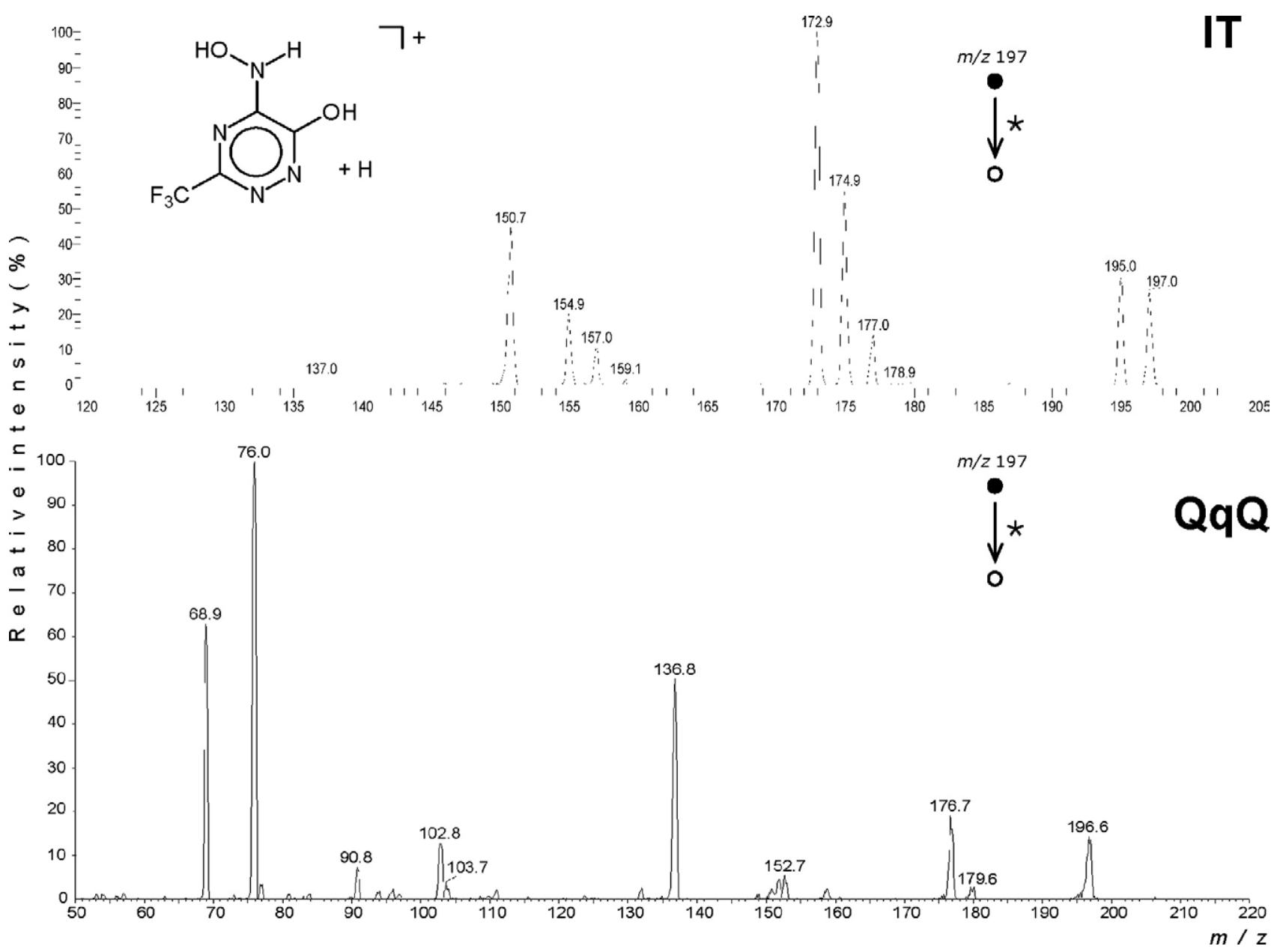

Figure 2. Comparison between ESI MS ${ }^{2}$ product ion spectra of $[\mathrm{M}+\mathrm{H}]^{+}$produced by $\mathbf{1}$ as a result of low-energy collision-induced dissociations occurring in a quadrupole ion trap (top) and in a triple quadrupole (bottom).

show a greater abundance of product ions than those produced in the ion trap.

The QqQ-MS ${ }^{2}$ spectrum of $[\mathbf{1}+\mathrm{H}]^{+}$is reported in Figure 2 (bottom). The two most intense product ions are at $m / z \quad 69$ and 76 that can be attributed to $\mathrm{C}_{2} \mathrm{HN}_{2} \mathrm{O}^{+} / \mathrm{CF}_{3}^{+}$and $\mathrm{F}_{2} \mathrm{C}^{+}-\mathrm{C} \equiv \mathrm{N}$, respectively. The product ions at $m / z 137$, also detected in the ion trap but with a very low abundance (Figure 2, top), constitute abundant CID product ions formed in the QqQ instrument. Accurate mass measurements have shown that they are attributed to elimination of three molecule of hydrofluoric acid from the protonated molecule. Although elimination of the first molecule of HF produces intense ions at $m / z 177$, the successive loss of $\mathrm{HF}$ is undetectable, suggesting that the species $[(\mathbf{1}+\mathrm{H})-2 \mathrm{HF}]^{+}$eliminates a further HF molecule with a very fast kinetics. In addition, the elimination of three HF molecules requires rearrangement of at least two hydrogen atoms.

The QqQ-MS ${ }^{2}$ spectrum of $\mathbf{1}$ also shows the presence of the species at $m / z 180$, with a relative abundance of about $3 \%$, which is much lower when low-energy collisions occur in the ion trap (Figure 2). These ions are due to loss of $17 \mathrm{u}$ from $[\mathrm{M}+\mathrm{H}]^{+}$and are formed by compounds 1, 3, and 4, all of them bearing an oxygen atom at position 6 of the triazine ring. Accurate mass measurements have established that they are due to elimination of $\cdot \mathrm{OH}$ from the protonated molecules. It means that radical cation species, i.e., $[(\mathrm{M}+\mathrm{H})-\mathrm{OH}]^{+\bullet}$, rarely observed under electrospray conditions [16], are produced as a result of low-energy CID.

The QqQ-MS ${ }^{2}$ spectra of $[2+\mathrm{H}]^{+}$and $[3+\mathrm{H}]^{+}$are compared in Figure 3. Regarding compound 2, product ions common to those produced inside the ion trap are at $m / z 239\left(\left[(\mathrm{M}+\mathrm{H})-\mathrm{H}_{2} \mathrm{O}\right]^{+}\right), 219([(\mathrm{M}+\mathrm{H}-$ $\left.\left.\left.\mathrm{H}_{2} \mathrm{O}\right)-\mathrm{HF}\right]^{+}\right), 191\left(219-\mathrm{N}_{2}\right)$, and $144\left(\left[\left(\mathrm{M}+\mathrm{H}-\mathrm{H}_{2} \mathrm{O}\right)-\right.\right.$ $\mathrm{CF}_{3} \mathrm{CNI}^{+}$), whose elemental compositions have been confirmed by accurate mass measurements.

The ions at $m / z 144$ have a high intensity in the QqQ-MS ${ }^{2}$ spectrum, with a relative intensity of about $93 \%$, whereas it is $30 \%$ in the IT-MS ${ }^{2}$ spectrum. These are yielded by elimination of $\mathrm{CF}_{3} \mathrm{CN}$ from the species $\left[\mathrm{M}+\mathrm{H}-\mathrm{H}_{2} \mathrm{O}\right]^{+}$. This decomposition pathway is specific for 2 and it is not observed for all the other compounds. Low $m / z$ ions are undetectable in the ion trap, whereas they are very abundant in the QqQ-MS ${ }^{2}$ spectrum of 2, 


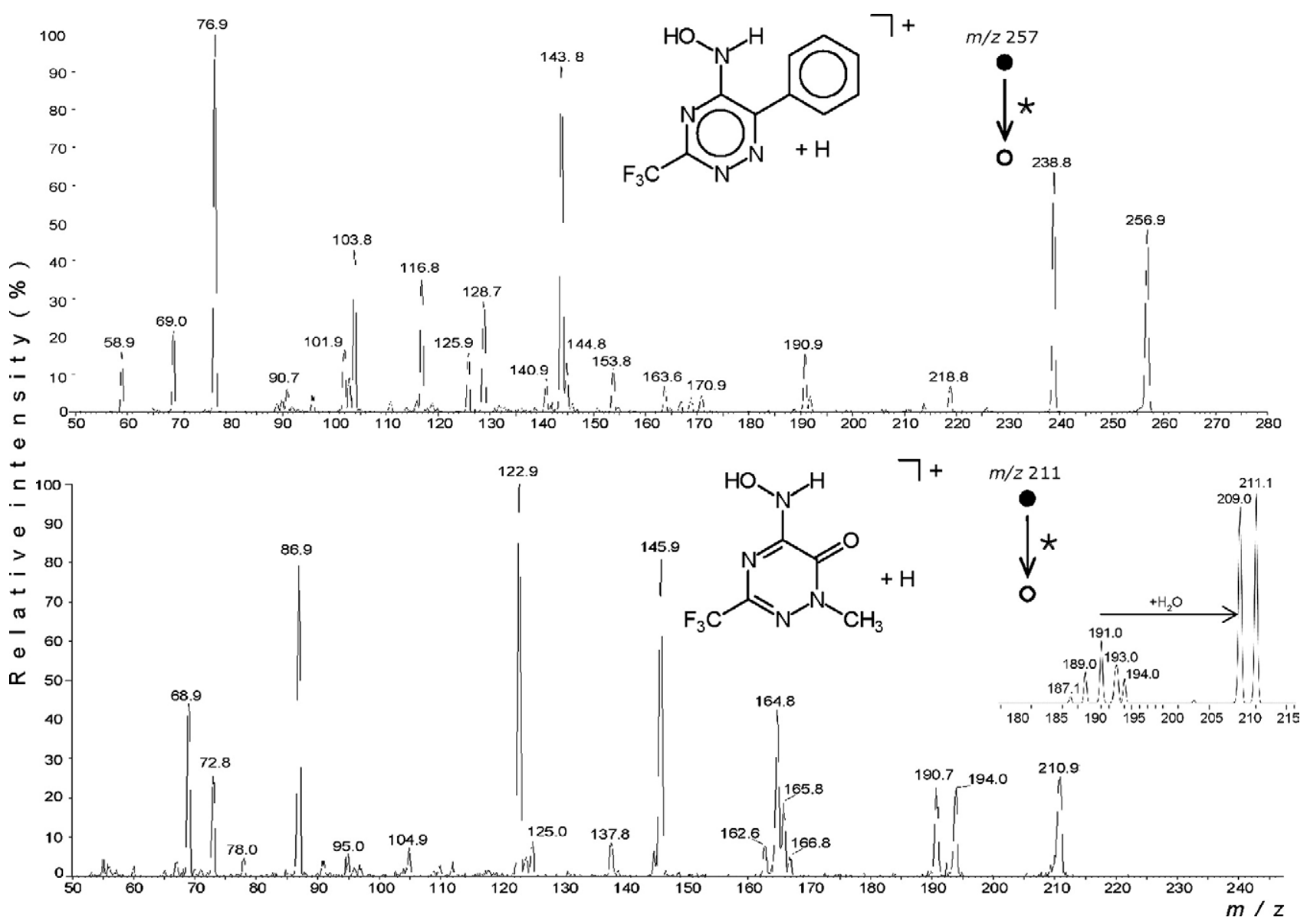

Figure 3. ESI QqQ-MS ${ }^{2}$ product ion spectra obtained as a result of low-energy collision-induced dissociations for protonated 2 (top) and 3 (bottom). A portion of the IT-MS ${ }^{2}$ mass spectrum of protonated 3 is reported in the inset.

whose base peak is at $\mathrm{m} / \mathrm{z} 77$ (Figure 3, top). Because analogous ions are not formed by the other compounds, those at $\mathrm{m} / \mathrm{z} 77$ can be attributed to the phenyl cation. Other product ions present both in the IT-MS ${ }^{2}$ and QqQ-MS $^{2}$ spectra are at $m / z$ 104, 117, and 129. They have been attributed to $\left[\mathrm{C}_{7} \mathrm{H}_{6} \mathrm{~N}\right]^{+},\left[\mathrm{C}_{7} \mathrm{H}_{5} \mathrm{~N}_{2}\right]^{+}$, and $\left[\mathrm{C}_{8} \mathrm{H}_{5} \mathrm{~N}_{2}\right]^{+}$, respectively.

However, differently by its IT-MS ${ }^{2}$ spectrum-which shows a very scarce fragmentation - the QqQ-MS ${ }^{2}$ spectrum of protonated 3 shows a wide variety of ions (Figure 3, bottom). Those at $\mathrm{m} / \mathrm{z} 123(100 \%), 87(80 \%)$, and $146(83 \%)$ are the most abundant ones. Their origin and composition have been determined by $\mathrm{MS}^{n}$ measurements in the ion trap and by accurate mass measurements. $[3+\mathrm{H}]^{+}$can eliminate HF or, alternatively, water and CO, yielding the species at $\mathrm{m} / \mathrm{z} 191$ and 165, respectively. This latter can follow two distinctive decomposition pathways: one consists of the elimination of $\mathrm{CH}_{2} \mathrm{~N}_{2}$, thus forming ions at $\mathrm{m} / \mathrm{z} 123$, as shown by IT-MS ${ }^{3}$ measurements. Alternatively, through consecutive eliminations of $\mathrm{N}_{2}$ and $\mathrm{CF}_{2}$, ions at $\mathrm{m} / z 165$ can yield the cations at $\mathrm{m} / \mathrm{z} 87$. As already observed for $\mathbf{1}, \mathbf{3}$ and $\mathbf{4}$ also show a prominent loss of a hydroxyl radical that in all cases is much more abundant when CIDs occur in the triple quadrupole than in the ion trap. The species $[(3+\mathrm{H})-\mathrm{OH}]^{+}$have an $\mathrm{m} / \mathrm{z}$ value equal to 194 . In the IT-MS ${ }^{2}$ and QqQ-MS ${ }^{2}$ product ion spectra their relative intensities are about 5 and $20 \%$, respectively (Figure 3, bottom and inset).

As a result of CID occurring in the triple quadrupole, $[4+\mathrm{H}]^{+}$decomposes through the elimination of a hydroxyl radical, whereas other first-generation product ions are not observed. The resulting ions $[(4+\mathrm{H})-\mathrm{OH}]^{+}$ have a relative intensity of about $18 \%$. These oddelectron cations may follow two decomposition routes, both involving elimination of radicals: in fact, the $\cdot \mathrm{CF}_{3}$ and $\mathrm{HCO}^{\circ}$ species can be lost, yielding even-electron cations at $m / z 225$ and 265 , respectively. These latter can lose a $\mathrm{CH}_{2} \mathrm{~N}_{2}$ molecule producing the species at $\mathrm{m} / \mathrm{z} 223$ that constitute the most intense peak in the QqQ-MS ${ }^{2}$ spectrum of $[4+\mathrm{H}]^{+}$. Fragmentation pathways of $[4+\mathrm{H}]^{+}$occurring both in the ion trap and in the QqQ mass spectrometer are reported in Scheme 2.

\section{Gas-Phase Behavior of Anions Produced by ESI of Compounds 1-4}

Deprotonated molecules $[\mathrm{M}-\mathrm{H}]^{-}$of compounds 1-4 have been produced by electrospray ionization and 


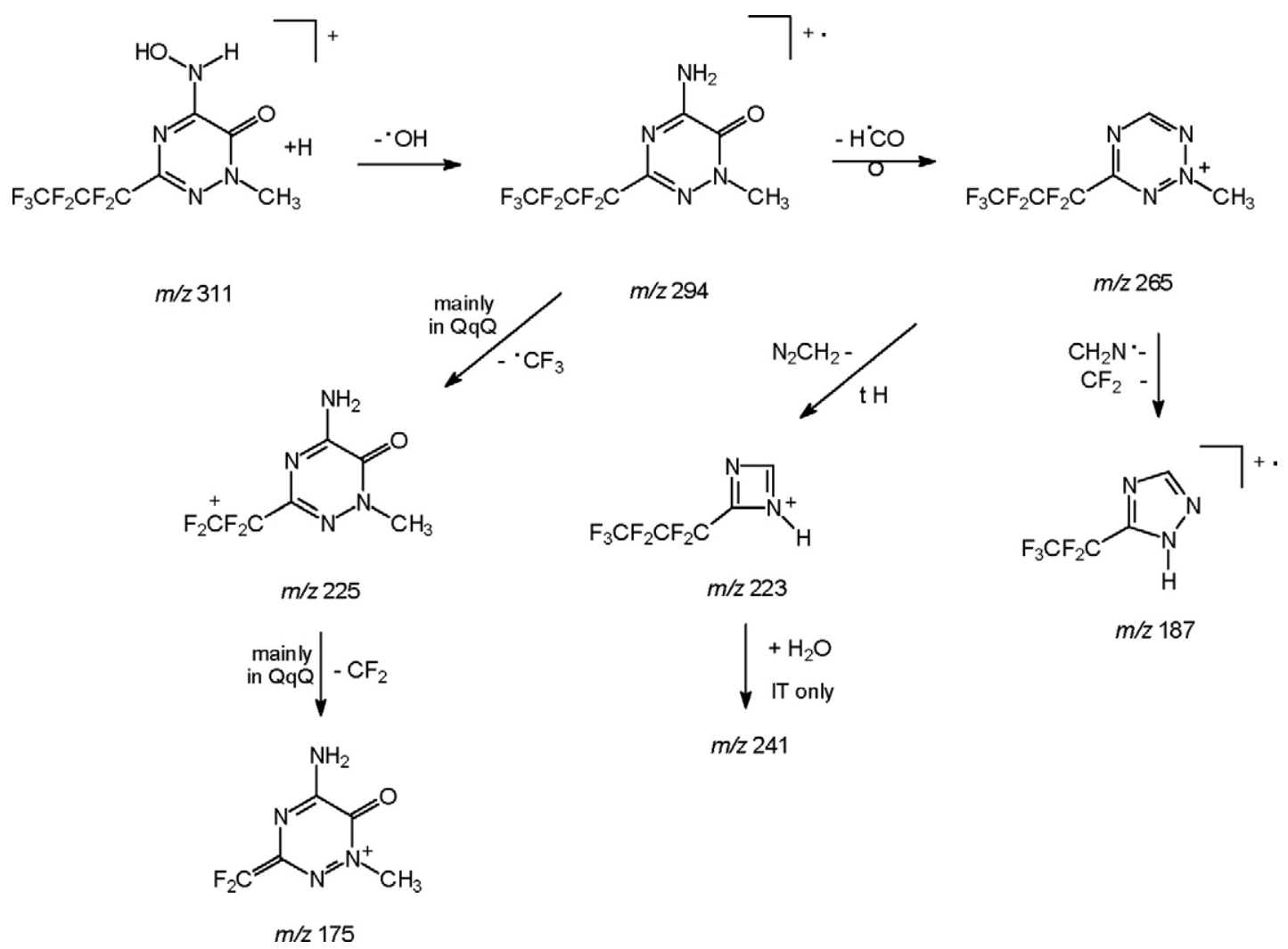

Scheme 2.

studied both in an ion trap and in a triple quadrupole instrument. In comparison with protonated molecules, two main differences can be highlighted in their gasphase behavior: (1) hydration reactions, observed for cations in IT-MS ${ }^{2}$ experiments, do not occur for anions; and (2) successive eliminations of $\mathrm{HF}$, which are important gas-phase decompositions of cations, are not observed for anions.

Decomposition reactions of deprotonated molecules of compounds 1-4 are initiated by loss of a hydroxyl radical and proceed through eliminations of neutral species (Figure 4). It follows that most product ions formed as a result of $\mathrm{MS}^{n}$ experiments are radical anions. Some examples of radical anions produced by ESI have been described for glycosides $[17,18]$, nitro compounds $[19,20]$, diuretics [21], and others.

The IT-MS ${ }^{2}$ spectrum of $[\mathbf{1}-\mathrm{H}]^{-}(m / z$ 195) shows a prominent loss of $17 \mathrm{u}$ yielding the most abundant ions at $m / z$ 178. Accurate mass measurements have confirmed that they are due to the loss of a ${ }^{\circ} \mathrm{OH}$ radical. Theoretical calculations, carried out on $\mathbf{1}$ deprotonated at different atoms, have shown that proton abstraction is more favored from the hydroxyl group in position 6 of the triazine ring, followed by the nitrogen and the oxygen of the hydroxylamino moiety (Figure 1, bottom row and Table 1). By considering the large energy difference, deprotonation at the hydroxylamino oxygen atom is highly unfavored.
When radical anions $[(\mathbf{1}-\mathrm{H})-\mathrm{OH}]^{-\bullet}$ are selected as precursors for $\mathrm{MS}^{3}$ measurements in the ion trap, two product ions are detected: one at $\mathrm{m} / \mathrm{z} 150(100 \%)$ and another at $m / z 151(18 \%)$. The use of the Orbitrap allowed us to determine that they are produced by losses of $\mathrm{CO}$ and $\mathrm{HCN}$, respectively. Elimination of $\mathrm{N}_{2}$ occurs only from the ions at $m / z 150$, as shown by $\mathrm{MS}^{4}$ measurements.

Similarly, the QqQ-MS ${ }^{2}$ spectrum of $[\mathbf{1}-\mathrm{H}]^{-}$shows a prominent loss of $17 \mathrm{u}$, but the most abundant ions are at $m / z 150$, already described for the ion trap. All the QqQ-MS ${ }^{2}$ spectra produced by the species $[\mathrm{M}-\mathrm{H}]^{-}$of compounds 1-4 show abundant ions at $m / z 66$ that are undetectable in $\mathrm{MS}^{2}$ spectra obtained by the ion trap. When these latter ions are produced in the ESI source by CID in source fragmentation and detected by the Orbitrap, the most probable elemental composition was $\mathrm{C}_{2} \mathrm{~N}_{3}$. By considering the molecular structure of compounds 1-4, the formation of this species should require important rearrangement reactions in their skeleton.

The IT-MS ${ }^{2}$ spectrum of $[2-\mathrm{H}]^{-}(m / z 255)$ shows the most intense ions at $m / z 237$ (Figure 4, top). An accurate examination of the spectrum reveals that it has a shoulder on the right side. Indeed, high-resolution, accurate mass measurements show two peaks at $\mathrm{m} / \mathrm{z}$ 238.0470 and 237.0392, with 28:100 intensity ratio, due to losses of ${ }^{\bullet} \mathrm{OH}$ and water, respectively. Thus, for the deprotonated molecule $[2-\mathrm{H}]^{-}$, the elimination of wa- 


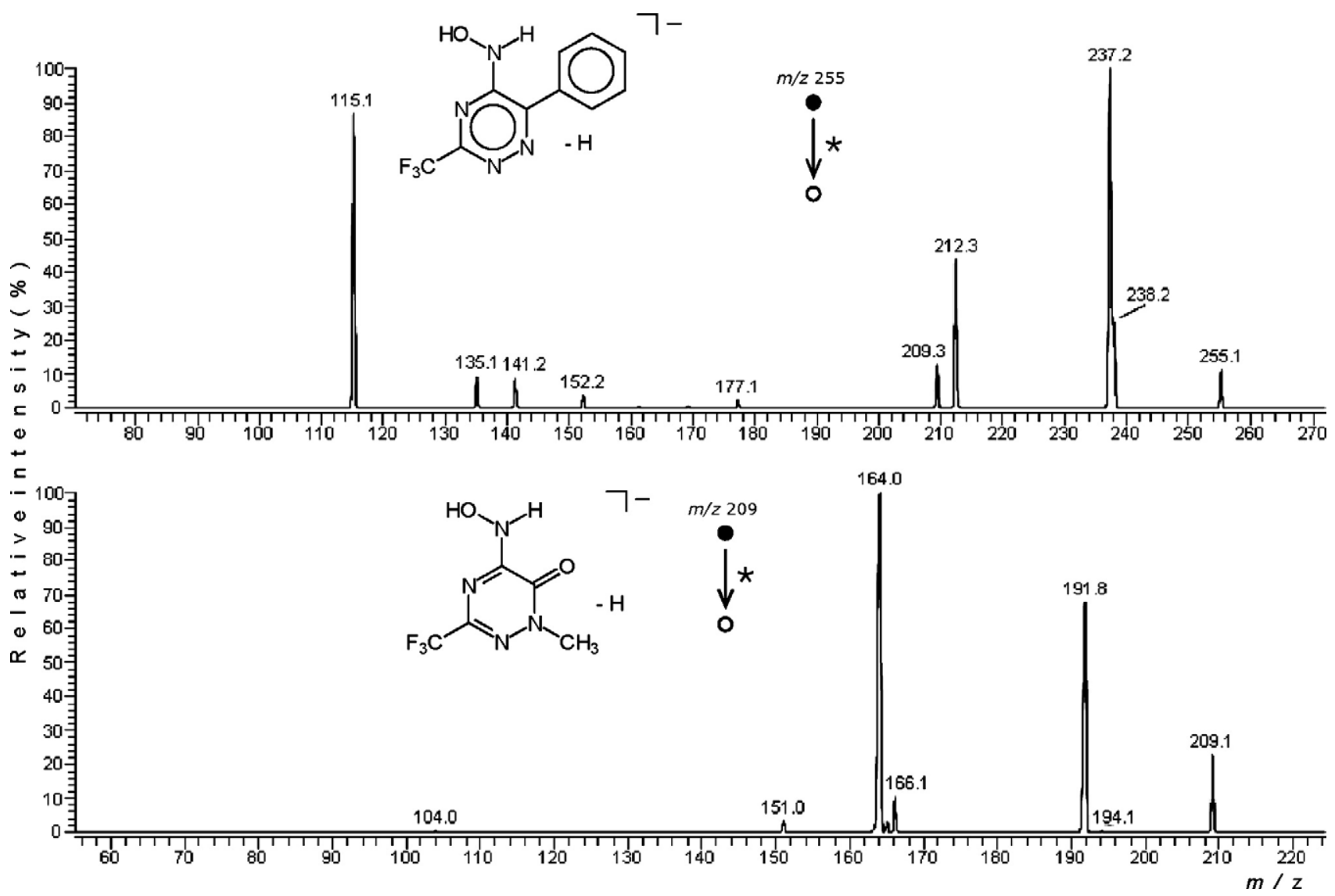

Figure 4. ESI IT-MS ${ }^{2}$ product ion spectra obtained for deprotonated 2 (top) and 3 (bottom).

ter is much higher than that of ${ }^{\bullet} \mathrm{OH}$. Similarly to positive ions, the proximity effect of the pendant phenyl to the hydroxylamino group is the driving force for the elimination of water with the formation of a tricyclic system, thus suggesting that deprotonation does not involve the exocyclic $\mathrm{OH}$ group. In turn, ions $\left[(2-\mathrm{H})-\mathrm{H}_{2} \mathrm{O}\right]^{-}$can lose $\mathrm{N}_{2}$, yielding the species at $\mathrm{m} / \mathrm{z}$ 209. Distinctively from the other deprotonated compounds, $[2-\mathrm{H}]^{-}$may fragment through elimination of isocyanic acid (HOCN) forming ions at $\mathrm{m} / \mathrm{z} 212$. The formation of both ions at $\mathrm{m} / \mathrm{z} 212$ and 209 occurs exclusively inside the ion trap. Other abundant ions present in the IT-MS ${ }^{2}$ product ion spectrum of $[2-\mathrm{H}]^{-}$ are at $m / z 115$ (Figure 4, top), due to the radical anion $\mathrm{C}_{8} \mathrm{H}_{5} \mathrm{~N}^{-\bullet}$ (calcd 115.0427, measured 115.0426), reasonably containing the exocyclic nitrogen atom.

Similarly to that occurring in the ion trap, the QqQ$\mathrm{MS}^{2}$ product ion spectrum of $[2-\mathrm{H}]^{-}$shows abundant ions at $m / z 115$ that in this case constitute the base peak. On the contrary, elimination of a hydroxyl group is unfavored in the triple quadrupole because it results from the relative abundance $(8 \%)$ of ions at $\mathrm{m} / \mathrm{z} 237$, whereas the loss of water is undetectable.

Elimination of ${ }^{\bullet} \mathrm{OH}$ is a major decomposition reaction also occurring in the ion trap for $[3-\mathrm{H}]^{-}$, yielding ions at $\mathrm{m} / \mathrm{z} 192$ (Figure 4, bottom). These latter further decompose by elimination of $\mathrm{CO}$ thus producing the species at $\mathrm{m} / \mathrm{z} 164$ that constitute the most intense peak in the $\mathrm{MS}^{2}$ spectra obtained both by IT and QqQ mass spectrometers (Figure 4, bottom, and Scheme 3). Because the ions at $\mathrm{m} / \mathrm{z} 192$ are undetectable when collision-induced dissociations occur in the triple quadrupole, it follows that they lose $\mathrm{CO}$ with a kinetics faster than the flight time of the ions in the QqQ system.

After elimination of $\mathrm{OH}^{\bullet}$ and $\mathrm{CO}$, the decomposition pathways involve the loss of $28 \mathrm{u}$, which accurate mass

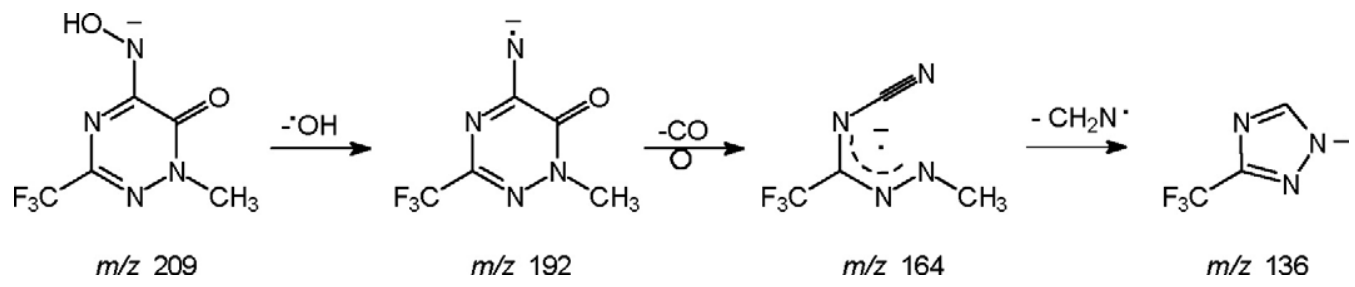

Scheme 3. 
measurements showed to be attributable to $\mathrm{CH}_{2} \mathrm{~N}_{2}$. The ions so formed (i.e., $m / z$ 136) have high abundance $(90 \%)$ in the QqQ-MS ${ }^{2}$ spectrum, whereas in the ion trap they are detectable only as a result of $\mathrm{MS}^{3}$ of the species at $m / z 164$ (Scheme 3).

The gas-phase behavior of $[4-\mathrm{H}]^{-}$strictly resembles that of $[3-\mathrm{H}]^{-}$, with analogous ions but shifted by $100 \mathrm{u}$. The only significant difference between them is the abundance of the $[(\mathrm{M}-\mathrm{H})-\mathrm{OH}]^{-}$ions in their corresponding IT-MS ${ }^{2}$ spectra: it is $70 \%$ for $[3-\mathrm{H}]^{-}$ (Figure 4, bottom) and only $1 \%$ for $[4-\mathrm{H}]^{-}$. Also their QqQ-MS ${ }^{2}$ spectra are similar, but the abundance of the ions $\left[(\mathrm{M}-\mathrm{H})-\mathrm{OH}-\mathrm{CO}-\mathrm{CH}_{2} \mathrm{~N}\right]^{-\bullet}$ is much higher for 3 $(\mathrm{m} / \mathrm{z} 136,95 \%)$ than for $4(\mathrm{~m} / \mathrm{z} 236,20 \%)$.

\section{Conclusion}

This study has allowed us to investigate the gas-phase ion chemistry of a new series of fluorinated 1,2,4triazines. The decomposition pathways of protonated and deprotonated molecules, occurring as a result of low-energy collision-induced dissociations in an ion trap and in a QqQ mass spectrometer, have shown interesting features depending on the nature and structure of precursor ions. The use of high-resolution, accurate mass measurements, MS $^{n}$ experiments, and theoretical calculations allowed us to define both the nature and the composition of product ions formed in their decomposition pathways. The occurrence of elimination/hydration reactions followed by positive ions in the ion trap is noteworthy. These reactions, which consist of elimination of HF molecules and addition of water, cause the formation of puzzling ions, differing $2 \mathrm{u}$ from each other, in the IT-MS ${ }^{n}$ spectra. Loss of a hydroxyl radical from species $[\mathrm{M}+\mathrm{H}]^{+}$also occurs; it is more abundant in the QqQ-MS ${ }^{2}$ spectra than in the IT-MS ${ }^{2}$ spectra.

Low-energy collision-induced dissociations of deprotonated molecules are dominated by odd-electron anions whose formation is initiated by loss of a hydroxyl radical from $[\mathrm{M}-\mathrm{H}]^{-}$.

This study has shown that the combination of different experimental and theoretical approaches is a useful tool for investigating gas-phase ion chemistry of heterocyclic compounds such as fluorinated triazines.

\section{Acknowledgments}

The authors gratefully acknowledge financial support through the Italian MIUR within the National Research Project "Dalle singole molecole a complessi e nanostrutture: struttura, chiralità, reattività e teoria" (PRIN 2006) and the Universities of Siena and Palermo.

\section{References}

1. Ronchi, S.; Prosperi, D.; Compostella, F.; Panza, L. Synthesis of Novel Carborane-Hybrids Based on a Triazine Scaffold for Boron Neutron Capture Therapy. Synlett 2004, 1007-1010.

2. Oliva, J. M.; Azenha, E. M. D. G.; Burrows, H. D.; Coimbra, R.; de Melo, J. S. S.; Canle, M. L.; Fernandez, M. I.; Santaballa, J. A.; Serrano-Andres,
L. On the Low-lying Excited States of Sym-Triazine-based Herbicides. Chem Phys Chem. 2005, 6, 306-314.

3. Filler, R.; Kobayashi, Y.; Yagupolskii, L. M. Organofluorine Compounds in Medicinal Chemistry and Biomedical Applications. Amsterdam: Elsevier, 1993.

4. (a) Chambers, R. D.; Sargent, C. R. Polyfluoroheteroaromatic Compounds. Adv. Heterocycl. Chem. 1981, 28, 1-71; (b) Differding, E.; Frick, W.; Lang, R. W.; Martin, P.; Schmit, C.; Veenstra, S.; Greuter, H. Fluorinated Heterocycles: Targets in the Search for Bioactive Compounds and Tools for Their Preparation. Bull. Soc. Chim. Belg. 1990, 99, 647-671; (c) Silvester, M. J. Recent Advances in Fluoroheterocyclic Chemistry. Adv. Heterocycl. Chem. 1994, 59, 1-38; (d) Burger, K.; Wucherpfennig, U.; Brunner, E. Fluoro Heterocycles with Five-membered Rings. Adv. Heterocycl. Chem. 1994, 60, 1-64; (e) Furin, G. G. Syntheses of Heterocyclic Compounds with Perfluoroalkyl Groups Based on Internal Perfluoroolefins. In: Targets in Heterocyclic Systems, Attanasi, O. A Spinelli, D., Eds.; Società Chimica Italiana: Rome, Italy, 1998; Vol. 2, pp 355-441; (f) Zhu, S. Z.; Wang, Y. L.; Peng, W. M.; Song, L. P.; Jin, G. F. Synthesis of Fluoroalkyl Substituted Heterocycles Using Fluorinecontaining Building Blocks. Curr. Org. Chem. 2002, 6, 1057-1096.

5. Hu, X. P.; Chen, H. L.; Zheng, Z. Ferrocene-based Chiral PhosphineTriazines: A New Family of Highly Efficient P,N Ligands for Asymmetric Catalysis. Adv. Synth. Catal. 2005, 347, 541-548.

6. Gamez, P.; Reedijk, J. 1,3,5-Triazine-based Synthons in Supramolecular Chemistry. Eur. J. Inorg. Chem. 2006, 2006(1), 29-42.

7. Giacomelli, G.; Porcheddu, A.; de Luca, L. [1,3,5]-Triazine: A Versatile Heterocycle in Current Applications of Organic Chemistry. Curr. Org. Chem. 2004, 8, 1497-1519.

8. Buscemi, S.; Pace, A.; Palumbo Piccionello, A.; Pibiri, I.; Vivona, N.; Giorgi, G.; Mazzanti, A.; Spinelli, D. Five-to-Six Membered Ring-Rearrangements in the Reaction of 5-Perfluoroalkyl-1,2,4-oxadiazoles with Hydrazine and Methylhydrazine. J. Org. Chem. 2006, 71, 8106-8113.

9. (a) Giorgi, G.; Salvini, L.; Ponticelli, F. Gas Phase Ion Chemistry of the Heterocyclic Isomers 3-Methyl-1,2-Benzisoxazole and 2-Methyl-1,3Benzoxazole. J. Am. Soc. Mass Spectrom. 2004, 15, 1005-1013; (b) Giorgi, G.; Ponticelli, F. Structural Characterization and Regiochemical Differentiation of $\alpha$-Cyanoethylindole Isomers in the Gas Phase. J. Am. Soc. Mass Spectrom. 2005, 16, 397-405.

10. Buscemi, S; Pace, A.; Palumbo Piccionello, A ; Macaluso, G.; Vivona, N Spinelli, D.; Giorgi, G. Fluorinated Heterocyclic Compounds. An Effective Strategy for the Synthesis of Fluorinated Z-Oximes of 3-Perfluoroalkyl6-phenyl-2H-1,2,4-triazin-5-ones via a Ring Enlargement Reaction of 3-Benzoyl-5-perfluoroalkyl-1,2,4-oxadiazoles and Hydrazine. J. Org. Chem. 2005, 70, 3288-3291.

11. Frisch, M. J.; Trucks, G. W.; Schlegel, H. B.; Scuseria, G. E.; Robb, M. A.; Cheeseman, J. R.; Montgomery, J. A., Jr.; Vreven, T.; Kudin, K. N.; Burant, J. C.; Millam, J. M.; Iyengar, S. S.; Tomasi, J.; Barone, V.; Mennucci, B.; Cossi, M.; Scalmani, G.; Rega, N.; Petersson, G. A. Nakatsuji, H.; Hada, M.; Ehara, M.; Toyota, K.; Fukuda, R.; Hasegawa, J.; Ishida, M.; Nakajima, T.; Honda, Y.; Kitao, O.; Nakai, H.; Klene, M.; Li, X.; Knox, J. E.; Hratchian, H. P.; Cross, J. B.; Bakken, V.; Adamo, C.; Jaramillo, J.; Gomperts, R.; Stratmann, R. E.; Yazyev, O.; Austin, A. J.; Cammi, R.; Pomelli, C.; Ochterski, J. W.; Ayala, P. Y.; Morokuma, K.; Voth, G. A.; Salvador, P.; Dannenberg, J. J.; Zakrzewski, V. G.; Dapprich, S.; Daniels, A. D.; Strain, M. C.; Farkas, O.; Malick, D. K.; Rabuck, A. D.; Raghavachari, K.; Foresman, J. B.; Ortiz, J. V.; Cui, Q.; Baboul, A. G.; Clifford, S.; Cioslowski, J.; Stefanov, B. B.; Liu, G.; Liashenko, A.; Piskorz, P.; Komaromi, I.; Martin, R. L.; Fox, D. J.; Keith, T.; Al-Laham, M. A.; Peng, C. Y.; Nanayakkara, A.; Challacombe, M.; Gill, P. M. W.; Johnson, B.; Chen, W.; Wong, M. W.; Gonzalez, C.; Pople, J. A. Gaussian 03, Revision D.02, Gaussian, Inc.: Wallingford, CT, 2004.

12. Becke, A. D. Density-functional Thermochemistry. III. The Role of Exact Exchange. J. Chem. Phys. 1993, 98, 5648-5652.

13. Callahan, M. P.; Crews, B.; Abo-Riziq, A.; Grace, L.; de Vries, M. S.; Gengeliczki, Z.; Holmes, T. M.; Hill, G. A. IR-UV Double Resonance Spectroscopy of Xanthine. Phys. Chem. Chem. Phys. 2007, 9, 4587-4591.

14. Giorgi, G.; Palumbo Piccionello, A.; Pace, A.; Buscemi, S. Hydration/ Elimination Reactions of Trapped Protonated Fluoroalkyl Triazines. J. Mass Spectrom. 2008, 43, 265-268.

15. Thevis, M.; Kohler, M.; Schlörer, N.; Schänzera, W. Gas Phase Reaction of Substituted Isoquinolines to Carboxylic Acids in Ion Trap and Triple Quadrupole Mass Spectrometers after Electrospray Ionization and Collision-induced Dissociation. J. Am. Soc. Mass Spectrom. 2008, 19, 151-158.

16. Vessecchi, R.; Crotti, A. E. M.; Guaratini, T.; Colepicolo, P.; Galembeck, S. E.; Lopes, N. P. Radical Ion Generation Processes of Organic Compounds in Electrospray Ionization Mass Spectrometry. Mini-Rev. Org. Chem. 2007, 4, 75-87.

17. Cuyckens, F.; Claeys, M. Determination of the Glycosylation Site in Flavonoid Mono-O-Glycosides by Collision-induced Dissociation of Electrospray-Generated Deprotonated and Sodiated Molecules. J. Mass Spectrom. 2005, 40, 364-372.

18. Es-Safi, N.-E.; Kerhoas, L.; Ducrot, P.-H. Application of Positive and Negative Electrospray Ionization, Collision-induced Dissociation and Tandem Mass Spectrometry to a Study of the Fragmentation of 6-Hydroxyluteolin 7-O-glucoside and 7-O-glucosyl-( $1 \rightarrow 3)$-glucoside Rapid Commun. Mass Spectrom. 2005, 19, 2734-2742.

19. Justes, D. R.; Talaty, N.; Cotte-Rodriguez, I.; Cooks, R. G. Detection of Explosives on Skin Using Ambient Ionization Mass Spectrometry. Chem. Commun. 2007, 33, 2142-2144. 
20. Danikiewicz, W.; Bienkowski, T.; Wojciechowski, K. Application of Electrospray Ionization Mass Spectrometry for Studies of Anionic o-Adducts of Aromatic Nitrocompounds. Tetrahedron Lett. 2004, 45, 931-934.
21. Thevis, M.; Schänzer, W.; Schmickler, H. Effect of the Location of Hydrogen Abstraction on the Fragmentation of Diuretics in Negative Electrospray Ionization Mass Spectrometry. J. Am. Soc. Mass Spectrom. 2003, 14, 658-670. 